\title{
Influence of the quality implementation of a physical education curriculum on the physical development and physical fitness of children
}

\author{
Gregor Starc ${ }^{*+}$ and Janko Strel ${ }^{\dagger}$
}

\begin{abstract}
Background: This study was constructed as a comparison group pre-test/post-test quasi-experiment to assess the effect of the implementation of the PE curriculum by specialist PE teachers on children's physical development and physical fitness.

Methods: 146 classes from 66 Slovenian primary schools were assigned to quasi-test (71) and quasi-control (75) groups. Data from the SLOFIT database was used to compare the differences in physical fitness and development between groups of children whose PE lessons were delivered by specialist PE teachers from the second grade onwards (quasi-test, $n=950$ ) or by generalist teachers in all first three grades (quasi-control, $n=994$ ). The Linear Mixed Model was used to test the influence of specialist PE teachers' teaching.

Results: The quasi-control group showed significantly lower improvement of physical fitness by $-0.07 \mathrm{z}$-score units ( $95 \% \mathrm{Cl}-0.12$ to 0.02$)$ compared to the quasi-test group. A significant difference of $-0.20(-0.27$ to -0.13$)$ was observed in explosive strength, and of $-0.15(-0.23$ to -0.08$)$ in running speed, and in flexibility by $-0.22(-0.29$ to -0.14). No significant differences in physical development were observed.

Conclusions: Specialist PE teachers were more successful than generalist teachers in achieving greater improvement of children's physical fitness, but no differences were observed in physical development of quasi-test and quasi-control group.
\end{abstract}

\section{Background}

Obesity, poor physical fitness of children and their causal dependency are associated with many preventable diseases and present a serious current and future public health problem [1]. Regular and quality physical activity during childhood is one part of the equation (quality nutrition being the other) that can lead to improvements in numerous physiological and morphological variables in children [2]. In addition, there are also numerous other benefits of physical activity on children's psychological development [3-5], lifestyle development [6-8], social development $[9,10]$ and cognitive development [11-13]. A considerable part of children's physical activity is presently allocated to regular physical education (PE) classes in schools [14], because economic

\footnotetext{
* Correspondence: gregor.starc@guest.arnes.si

† Contributed equally

Faculty of Sport, University of Ljubljana, Gortanova 22, SI-1000 Ljubljana, Slovenia
}

(c) 2012 Starc and Strel; licensee BioMed Central Ltd. This is an Open Access article distributed under the terms of the Creative Commons Attribution License (http://creativecommons.org/licenses/by/2.0), which permits unrestricted use, distribution, and reproduction in any medium, provided the original work is properly cited. pressures [15] and parental concern for safety $[16,17]$
often reduce children's physical activity in non-school settings. In Slovenia, this is especially problematic in the first years of school, when PE classes are frequently delivered by generalist teachers without appropriate PE teaching competences [18-25], because this can result in less effective physical fitness development, followed by increased risks of obesity and diminishing of motor skills and functional abilities, which then can lead to unfavourable results in adulthood [26].

The existing evidence suggests that activities for children have to be organised to be effective, because idle leisure, e.g. summer holidays, seem to be counterproductive for physical and motor development $[27,28]$, and because there seem to be no difference between obese and non-obese children in unorganised leisure-time activities [29]. PE as an organised and compulsory activity could, therefore, be one of few possible environments 
for the successful intervention against the health-risk problems related to physical inactivity and obesity.

Often authorities try to improve negative trends with special interventions in schools but such programmes usually fail to produce considerable positive long-term effects [30]. The interventions usually include the allocation of additional time to physical education [31-33], specially designed after-school programmes $[34,35]$, or a changed design of PE delivery [36]. However, this brings demands for additional temporal, spatial, human and economic resources.

In addition, the existing evidence shows that programmes with compulsory physical activity components, such as regular PE classes, seem to be superior to those based on educational interventions, as adherence is guaranteed [37]. Therefore, we tried to determine whether the negative trends can be improved within the educational system and existing PE curriculum, without time-limited and thus economically less effective external interventions or special voluntary intervention programmes, and with the partial allocation of already existing human resources in schools.

We believe that quality of PE depends on five factors: allocated time, available facilities and equipment, the contents of the PE curriculum, the number of children per teacher, and teacher competencies. Among these factors, we see that PE curriculum and its quality implementation are the determining factors of the PE outcomes. The official PE curriculums form the framework of possible interventions and in some cases can limit the effect of the subject. In the Slovenian case, the PE curriculum underemphasises health-related contents or considers them unintended collateral effects of the development of motor skills and the acquirement of sporting skills. The implementation of the curriculum, in contrast, depends on teachers' teaching competencies; our goal was to see whether specialist PE teachers' competencies have an effect on children's physical fitness and physical development by excluding the other four factors. During their 5 years of study, Slovenian generalist teachers receive between 175 and $355 \mathrm{~h}$ of PE teaching-related instruction, while the specialist PE teachers receive over $1,600 \mathrm{~h}$; we attempted to verify whether this discrepancy in time allocated to the development of teaching competencies influences the quality and effectiveness of planning and teaching competencies of both profiles.

In Slovenia, specialist PE teachers are allowed to teach $\mathrm{PE}$ in the first 3 years of primary school, but this is currently considered a supplemental programme, requiring additional funding from parents or/and local communities, and the consent of the school board. If the school decides to have a specialist PE teacher teaching in the first 3 years, the classroom teacher has to be present in the class during these lessons. This gave us the opportunity to compare the physical fitness and physical development of the minority of Slovenian children whose PE classes in the first years of school are delivered by specialist PE teachers and of the majority of children who are taught only by generalist teachers.

\section{Methods}

\section{Participants}

The sample consisted of 146 second-grade classes from 33 quasi-test and 33 quasi-control schools with 950 children in the first group and 994 children in the latter one (Figure 1). The sample included 453 girls and 497 boys in the quasi-test group and 483 girls and 511 boys in quasi-control one. The baseline age in both groups was almost identical $($ mean $=6.78, \mathrm{SD}=0.30)$.

\section{Procedures}

In 2008, a questionnaire on school environment was sent to all 450 Slovenian primary schools and was completed by school principals or PE teachers. Among the

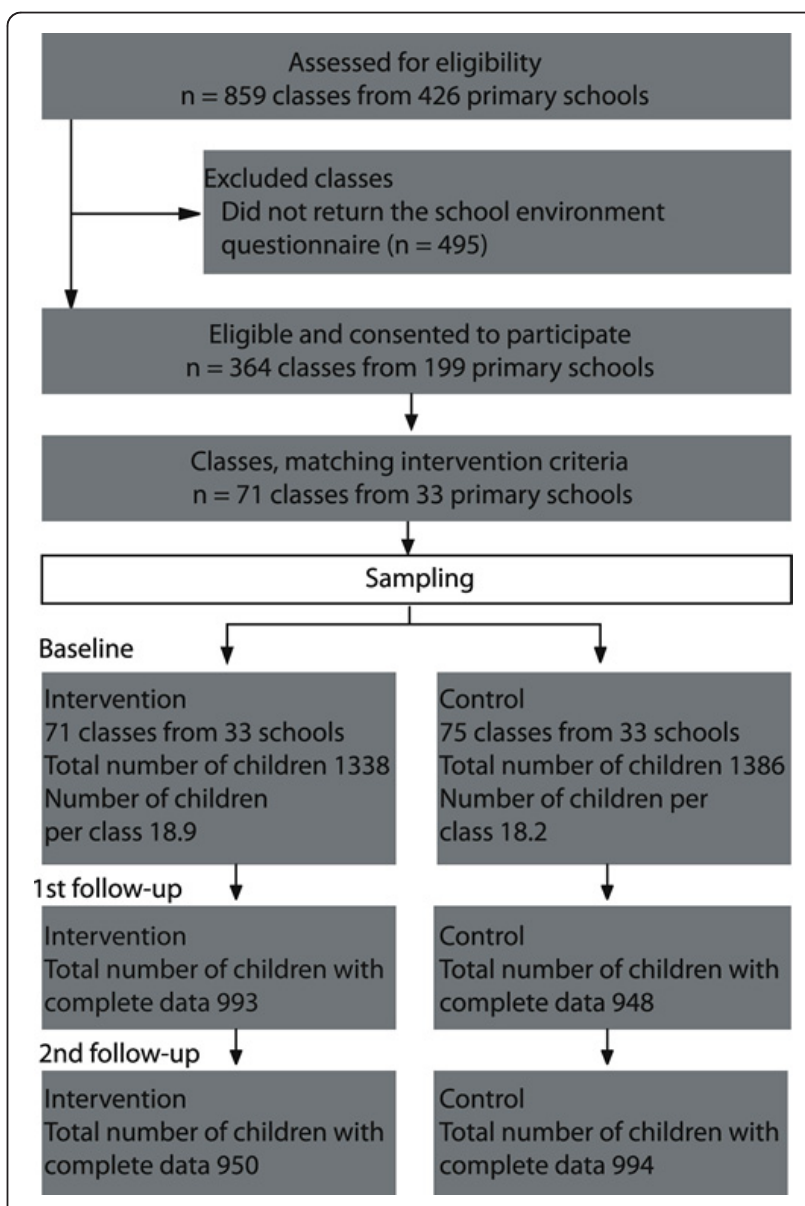

Figure 1 Flow of school classes and sample sizes throughout the quasi-experiment. 
199 schools that returned the questionnaire, the majority had PE in the first three grades delivered by generalist teachers, while 33 had PE delivered by specialist PE teachers from the second grade onwards. The secondgrade classes from the latter schools were assigned to the quasi-test group. We then paired the quasi-test classes with quasi-control classes from the neighbouring schools to exclude as many environmental factors as possible. PE and classroom teachers both followed the same official PE curriculum and had very similar teaching environments regarding facilities and equipment (all included primary schools have two gyms with standardised equipment), and number of children in the classes (see Figure 1); all classes had three compulsory 45-minute lessons of PE per week.

We used the SLOFIT database to extract data of the eight motor tests and the three anthropometric measurements for every child included in the first, second and third years of schooling. The results of the motor tests were used to calculate the physical fitness index (PFI) and the body mass index (BMI) for every child in all three grades. Baseline and both follow-up measurements took place at schools during PE lessons in April 2007, 2008 and 2009. The SLOFIT system, implemented in 1987 and formerly known as the Sports Educational Chart, is a Slovenian monitoring system of children's motor and physical development. Every April, qualified PE teachers with a completed anthropometry measurement course perform the measurements in all primary and secondary schools as required by the PE curriculum, following the official measurement protocol [38]. The SLOFIT test battery includes eight motor tests (arm-plate tapping (APT), standing long jump (SLJ), polygon backwards (PB), sit-ups (SU), standing reach touch (SRT), bent arm hang (BAH), 60-meter run $(60 \mathrm{~m})$ and 600meter run $(600 \mathrm{~m})$ ), and three anthropometric measurements (height $(\mathrm{BH})$, weight $(\mathrm{BW})$ and triceps skinfold thickness (TSF)). Measurements are always organised in school gyms between 08:00 and 14:00. Subjects were weighed barefoot in their shorts and T-shirts to the nearest $0.1 \mathrm{~kg}$ with portable scales of various brands; height was measured with stadiometers of various brands to the nearest $0.1 \mathrm{~cm}$; triceps skinfold was measured with Holtain-Tanner callipers to the nearest $\mathrm{mm}$. All instruments were calibrated once at the beginning of the measurements. Data were checked to detect coding errors. In order to include and evaluate the children's measurements in the SLOFIT system, and to use the data for scientific purposes, children need the written consent of their parents; throughout the existence of this system, the response rates in primary schools have remained above $94 \%$. The SLOFIT database currently includes more than five million sets of measurements and grows at a rate of approximately 210,000 sets of measurements per year.

\section{Statistical analyses}

All statistics were computed using the PASW 18 for Mac statistical software package (SPSS Inc., Chicago, IL). Since this was a quasi-experiment, we used the Linear Mixed Model procedure to test the influence of specialist PE teachers' teaching (PTE) on the physical fitness and physical development of children by excluding gender and age, and by using teacher and age in months as a fixed effect. Because there are individual differences among PE teachers, PTE was also used as a random effect along with schools. The physical fitness of children was assessed according to PFI, which was computed by averaging the z-scores of all eight motor tests. BMI was calculated from body weight and height, but the BMI z-score was used in the analysis. Linear Mixed Models were used to test for dependent variable PTE with independent variables. The latter consisted of two main primary outcome variables (PFI and BMI zscore), and secondary outcome variables (z-transformed results of individual motor tests in all three grades). Preliminary tests to identify possible effects of gender and school grade on PFI, BMI and secondary outcome variables were not performed, since z-scores of all tests were calculated by the RANKIT procedure according to school grade and gender. Several models and unstructured covariance matrix were tested separately for each dependent variable to find the best-fit model.

\section{Ethics approval}

This study was funded by the Slovenian Ministry of Education and Sport and was approved by the Faculty of Sport of the University of Ljubljana ethics committee. Written positive consent of parents was provided for the use of data in scientific purposes. All procedures and methods in this study conformed to the ethics guidelines established by the World Medical Association's Declaration of Helsinki and the subsequent revisions.

\section{Results}

Table 1 shows the results of the outcomes at baseline and both follow-ups, including adjusted differences at follow-ups.

In comparison to the quasi-test group, the quasi-control group showed significantly smaller improvement of physical fitness by $-0.07 \mathrm{z}$-score units (95\% confidence interval -0.12 to 0.02 ). In individual motor abilities, the quasi-control group significantly lagged behind the quasi-test group in relative explosive strength and running speed: in SLJ by $-0.20(-0.27$ to -0.13$)$ or $1.2 \%$ of mean baseline value and in $60 \mathrm{~m}$ by $-0.15(-0.23$ to $-0.08) \mathrm{z}$-score units or $0.5 \%$ of mean baseline value. The biggest difference occurred in relative flexibility (SRT), where the quasi-control group achieved poorer results by $-0.22 \mathrm{z}$-score units $(-0.29$ to -0.14$)$, representing an 
Table 1 Measurements of anthropometric and motor tests at baseline and follow-ups

\begin{tabular}{|c|c|c|c|c|c|c|c|c|}
\hline \multirow[b]{2}{*}{ Variables } & \multicolumn{3}{|c|}{ Quasi-test } & \multicolumn{3}{|c|}{ Quasi-control } & \multicolumn{2}{|c|}{ Adjusted difference at follow-ups* } \\
\hline & Baseline & Follow-up 1 & Follow-up 2 & Baseline & Follow-up 1 & Follow-up 2 & $95 \% \mathrm{Cl}$ & $P$ value \\
\hline PFI (z-score) & $0.02(0.60)$ & $0.06(0.65)$ & $0.08(0.66)$ & $-0.02(0.60)$ & $-0.04(0.64)$ & $-0.06(0.66)$ & $-0.07(-0.12,0.02)$ & 0.006 \\
\hline $\mathrm{BMI}(\mathrm{kg} / \mathrm{m} 2)^{* *}$ & $16.24(2.19)$ & $16.94(2.49)$ & $17.60(2.74)$ & $16.05(2.16)$ & $16.90(2.44)$ & $17.53(2.77)$ & $-0.05(-0.03,0.13)$ & 0.242 \\
\hline$\overline{\mathrm{TSF}}(\mathrm{mm})^{* *}$ & $10.53(4.15)$ & $11.73(4.91)$ & $12.43(5.05)$ & $10.63(4.23)$ & $11.64(4.83)$ & $12.24(5.25)$ & $0.02(-0.06,0.10)$ & 0.624 \\
\hline BW (kg) & $25.50(4.74)$ & $28.97(5.77)$ & $32.87(6.84)$ & $25.15(4.57)$ & $28.83(5.59)$ & $32.54(6.75)$ & $-0.03(-0.12,0.05)$ & 0.451 \\
\hline $\mathrm{BH}(\mathrm{cm})$ & $124.95(5.32)$ & $130.37(5.51)$ & $136.20(5.87)$ & $124.85(5.23)$ & $130.20(5.28)$ & $135.80(5.63)$ & $-0.04(-0.13,0.05)$ & 0.368 \\
\hline PT (rep/20s) & $22.61(3.55)$ & $25.94(3.84)$ & $29.01(3.91)$ & $22.46(4.00)$ & $25.92(4.38)$ & $28.98(4.36)$ & $-0.03(-0.11,0.04)$ & 0.351 \\
\hline SU (rep/60s) & $25.56(7.62)$ & $31.28(7.78)$ & $35.16(8.61)$ & $26.24(7.65)$ & $30.57(7.54)$ & $34.50(7.79)$ & $-0.02(-0.09,0.05)$ & 0.619 \\
\hline$\overline{\mathrm{SRT}}(\mathrm{cm})$ & $43.55(5.69)$ & $44.03(6.09)$ & $44.55(6.25)$ & $42.59(5.95)$ & $43.07(6.34)$ & $42.69(6.36)$ & $-0.22(-0.29,-0.14)$ & $<0.001$ \\
\hline $\mathrm{SLJ}(\mathrm{cm})$ & $120.69(17.07)$ & $133.34(17.62)$ & $142.69(18.55)$ & $117.97(17.58)$ & $128.60(17.67)$ & $138.08(19.03)$ & $-0.20(-0.27,-0.13)$ & $<0.001$ \\
\hline $\mathrm{AH}(\mathrm{s})$ & $21.80(18.92)$ & $27.99(22.62)$ & $30.84(23.87)$ & $21.51(17.53)$ & $26.09(20.28)$ & $30.42(23.57)$ & $-0.02(-0.09,0.06)$ & 0. \\
\hline $\mathrm{PB}(\mathrm{s})^{* *}$ & $22.51(6.84)$ & $17.82(4.87)$ & $16.08(4.55)$ & $22.04(6.63)$ & $18.02(5.04)$ & $16.38(4.89)$ & $-0.01(-0.07,0.07)$ & 0.883 \\
\hline$\overline{600 m(s)^{* *}}$ & $206.56(33.17)$ & $194.08(33.95)$ & $181.23(31.06)$ & $207.69(32.07)$ & $191.47(27.81)$ & $182.81(28.87)$ & $-0.05(-0.13,0.03)$ & 0.200 \\
\hline $60 \mathrm{~m}(\mathrm{~s})^{* *}$ & $13.10(1.20)$ & $12.28(1.16)$ & $11.67(1.08)$ & $13.26(1.36)$ & $12.47(1.20)$ & $11.88(1.12)$ & $-0.15(-0.23,-0.08)$ & $<0.001$ \\
\hline
\end{tabular}

Values are raw (SD) unless stated otherwise.

${ }^{*}$ Adjusted difference in average $z$-score of respective outcome between quasi-test and quasi-control group with $95 \%$ confidence interval and $\mathrm{P}$ value, adjusted for gender and grade in Linear Mixed Model with random effect for PTE and school

**Z-scores ranked by lowest value. Higher z-score value signifies better result

improvement of $2 \%$ of the mean baseline value of the quasi-test group. If observed through the percentage of change of baseline values to the second follow-up, the quasi-test group progressed 2.6 times more in PFI, 2.0 times more in SLJ, 1.8 times more in $60 \mathrm{~m}$ and even 4.1 times more in SRT than the quasi-control group. All other indicators of physical fitness from baseline to second follow-up showed a non-significant trend, but all in favour of the quasi-test group. Regarding physical development, no significant differences were observed between the quasi-test and the quasi-control group from baseline to the second follow-up.

\section{Discussion}

With this quasi-experiment, we were able to show that the existing PE curriculum, planned and delivered by specialist PE teachers with higher PE teaching competencies than generalist teachers, positively affects children's physical fitness; however, it does not have such a distinct effect on their body composition. To our knowledge, no research has been conducted this far to investigate the effect of the quality implementation of the existing PE curricula on children's PFI and BMI, although there have been attempts to test the efficacy of $\mathrm{PE}$ programmes according to the exposure to PE [31].

Our findings are congruent with the findings of some intervention studies that have proven that school interventions can work if they are appropriately implemented and delivered by qualified professionals [39], and that PE specialists provide more effective physical education than non-specialists [40].
The quasi-experiment showed that the planning and delivery of PE lessons by PE specialist teachers in comparison to generalist teachers resulted in a relative improvement of physical fitness in the quasi-test group in comparison to the quasi-control group.

The less distinct influence on body composition could be connected to the existing Slovenian PE curriculum [41], which focuses mostly on motor development and especially on muscular fitness, but less on health-related issues like obesity. Research on the Slovenian PE teachers' competencies revealed that they feel very competent in the area of motor development [42], while evidence from other countries shows that, because of their low confidence in PE teaching competencies, many classroom teachers would prefer PE teachers teaching their PE classes [22]. An additional argument in favour of the higher quality planning and implementation of $\mathrm{PE}$ curriculum by specialist PE teachers is the observation that the quasi-test group improved their motor skills despite the growing burden of their subcutaneous fat.

The existing curriculum also encourages anaerobic activities over aerobic ones and the quasi-experiment confirmed that specialist PE teachers were more effective in improving anaerobic abilities than the generalist teachers, while no difference in aerobic abilities was observed. Since the quasi-test group improved their explosive strength and speed significantly more than the quasi-control group, it could be argued that the implementation of PE classes by specialist teachers can have a long-term positive effect on the enhancement of bone mass, which is related to muscular fitness in the 
paediatric population [43-46]. Quality PE from the beginning of schooling is important in this regard, because the evidence shows that participation in regular and intensive physical activity should start before the pubertal growth spurt to achieve the maximum development of bone as well as muscle mass [47,48].

Because there is evidence that flexibility does not normally increase with age [49], the four times greater increase of this motor ability in the quasi-test group could be attributed to environmental factors, including the higher quality of lesson delivery by specialist PE teachers compared to generalist teachers. Although there is not much evidence on the effects of flexibility on children's health, this component of neuromotor fitness seems to lower the risks of injury $[50,51]$ and in this way contributes to children's health status.

The existing evidence proves that children in schools with fewer students per physical educator are more physically active during PE lessons [52]; this factor was not decisive in our case, since the average number of children per PE teacher was similar in both groups.

\section{Limitations}

There are limitations to our study, and care should be taken in generalising its results to different countries, since there are considerable differences in the organisation and contents of PE curricula worldwide. The study was a quasi-experiment and did not control for many important environmental and social factors influencing the physical and motor development of children, although we tried to control for those factors by sampling from neighbouring schools from similar social and natural environments. The schools from the intervention groups were not randomly selected but were included based on the return of the school environment questionnaire. We were also unable to gather the information on teachers' actual PE planning and teaching competencies, which surely influence the quality of curriculum delivery. We were not able to gather the information on the intensity levels of PE lessons, which undoubtedly affect the health outcomes. Also, we gathered no information on the actual role of generalist teachers in PE planning and the delivery of PE lessons by PE specialists. In our experience, classroom teachers are present in the gym with the PE specialist but limit their activity to occasional help in setting the teaching environment and managing children who do not participate in the activities due to health and other reasons; they leave the planning and/or delivering the lessons to the PE specialists. We are aware that the level of physical fitness and body composition are not the only factors determining physical activity and consequent health outcomes in adult life, but the nature of our study did not allow us to gather additional information on the psycho- social effects of quality PE. Although the quasi-test and control groups had identical amounts of PE lessons per year, we have no information whether the children's out-of-school activities affected the results. Finally, we acknowledge that the quality of PE teaching does not rely solely on the level of professional competencies acquired in the teaching education programmes, but also on the level of social and other competencies of teachers that remained unknown to us.

\section{Conclusions}

Our study shows that teachers' higher competencies in planning and delivering PE lessons positively contribute mostly to children's physical fitness and less to their body composition. The results suggest that specialist PE teachers seem to be more effective than generalist teachers in delivering of PE lessons, even if the learning environment, facilities and available equipment are very similar, if the curriculum is identical, and even with a similar number of children per teacher at PE lessons. Specialist PE teachers seem to deliver more effective PE lessons of seemingly higher intensity and have a consequently stronger positive effect on children's motor development, but not as significant an effect on their physical development. The contents of the curriculum are important in this regard, and we assume that a more balanced curriculum, including emphasis on health goals related to the decrease of children obesity, would have a stronger positive influence on the body composition of the quasi-test group. The main goal of PE should remain the enhancement of cardiovascular, motor and neuromotor fitness through vigorous physical activity, but some more emphasis should be put also on the promotion of positive health behaviours. Care must be taken not to base unrealistic aims for public health on school PE since teachers' primary task is teaching and not physical training or disease prevention; however, $\mathrm{PE}$ should not be ignored for its possible positive synergetic effects in the wider public health struggle against obesity and related health risks. To achieve more significant positive effects on body composition and consequent health, three 45-minute classes of PE per week seem to be insufficient, and we would suggest having five classes of at least 45 min per week with at least $60 \%$ of time spent on the level of moderate-to-vigorous physical activity. The evidence from other countries shows that the intensity of PE lessons is below recommended values, with Dutch children achieving 46.7\% [53] and some US children merely $8.6 \%$ [54] of PE time in moderate-to vigorous physical activity.

\section{Acknowledgements}

The research has been funded by the Ministry of Education of Sport of the Republic of Slovenia. 


\section{Authors' contributions}

IS conceived and designed the study. GS was responsible for recruitment, data collection, data entry, data analysis and drafting the manuscript. Both authors contributed to writing and approved the final manuscript.

\section{Competing interests}

The authors declare that they have no competing interests.

Received: 1 September 2011 Accepted: 20 January 2012 Published: 20 January 2012

\section{References}

1. Dietz WH: Health consequences of obesity in youth: Childhood. Pediatrics 1998, 101:518.

2. Owen CG, Nightingale CM, Rudnicka AR, Sattar N, Cook DG, Ekelund U, Whincup PH: Physical activity, obesity and cardiometabolic risk factors in 9- to 10-year-old UK children of white European, South Asian and black African-Caribbean origin: the Child Heart And health Study in England (CHASE). Diabetologia 2010, 53:1620-1630.

3. Fox KR: The self-esteem complex and youth fitness. Quest 1988, 40:230-246.

4. Backmand H, Kaprio J, Kujala UM, Sarna S, Fogelholm M: Physical and psychological functioning of daily living in relation to physical activity. A longitudinal study among former elite male athletes and controls. Aging Clin Exp Res 2006, 18:40-49.

5. Hassmen P, Koivula N, Uutela A: Physical exercise and psychological wellbeing: A population study in Finland. Prev Med 2000, 30:17-25.

6. Kjonniksen L, Anderssen N, Wold B: Organized youth sport as a predictor of physical activity in adulthood. Scand J Med Sci Sports 2009, 19:646-654.

7. Trudeau F, Laurencelle L, Shephard RJ: Is fitness level in childhood associated with physical activity level as an adult? Pediatr Exerc Sci 2009, 21:329-338.

8. Telama R, Yang XL, Hirvensalo M, Raitakari O: Participation in organized youth sport as a predictor of adult physical activity: A 21-year longitudinal study. Pediatr Exerc Sci 2006, 18:76-88

9. Strauss RS, Rodzilsky D, Burack G, Colin M: Psychosocial correlates of physical activity in healthy children. Arch Pediat Adol Med 2001, 155:897-902.

10. Gibbons SL, Ebbeck V, Weiss MR: Fair play for kids - effects on the moral development of children in physical-education. Res Q Exercise Sport 1995, 66:247-255.

11. Sallis JF, McKenzie TL, Kolody B, Lewis M, Marshall S, Rosengard P: Effects of health-related physical education on academic achievement: project SPARK Reston, VA, ETATS-UNIS: American Alliance for Health, Physical Education, Recreation and Dance; 1999.

12. Carlson SA, Fulton JE, Lee SM, Maynard LM, Brown DR, Kohl HW, Dietz WH: Physical education and academic achievement in elementary school: Data from the early childhood longitudinal study. Am J Public Health 2008, 98:721-727.

13. Trudeau F, Shephard R: Physical education, school physical activity, school sports and academic performance. Int J Behav Nutr Phys Act 2008, 5:10.

14. Bailey R: Physical education and sport in schools: a review of benefits and outcomes. J Sch Health 2006, 76:397-401.

15. Hardy LL, Kelly B, Chapman K, King L, Farrell L: Parental perceptions of barriers to children's participation in organised sport in Australia. $J$ Paediatr Child Heath 2010, 46:197-203.

16. Ollendick TH, King NJ, Frary RB: Fears in children and adolescents reliability and generalizability across gender, age and nationality. Behav Res Ther 1989, 27:19-26.

17. Kalish M, Banco L, Burke G, Lapidus G: Outdoor play: A survey of parent's perceptions of their child's safety. J Trauma 2010, 69:S218-S222.

18. DeCorby K, Halas J, Dixon S, Wintrup L, Janzen H: Classroom teachers and the challenges of delivering quality physical education. J Educ Res 2005, 98:208-220.

19. Janzen H, Halas J, Dixon S, DeCorby K, Booke J, Wintrup L: The quality of physical education in Manitoba schools: A 3 year study. Phys Health Educ J 2003 69:44.

20. Morgan PJ, Hansen V: Classroom teachers' perceptions of the impact of barriers to teaching physical education on the quality of physical education programs. Res Q Exercise Sport 2008, 79:506-516.
21. Sallis JF, McKenzie TL, Alcaraz JE, Kolody B, Faucette N, Hovell MF: he effects of a 2-year physical education program (SPARK) on physical activity and fitness in elementary school students. Sports, Play and Active Recreation for Kids. Am J Public Health 1997, 87:1328-1334.

22. Morgan $P$, Hansen $V$ : Recommendations to improve primary school physical education: Classroom teachers' perspective. J Educ Res 2007, 101:99-111.

23. Hardman K: The situation of physical education in schools: A European perspective. Hum Mov 2008, 9:5-18.

24. Hardman K: An up-date on the status of physical education in schools worldwide: Technical report for the World Health Organisation. Book An up-date on the status of physical education in schools worldwide: Technical report for the World Health Organisation City: WHO; 2007.

25. Barroso CS, McCullum-Gomez C, Hoelscher DM, Kelder SH, Murray NG: Selfreported barriers to quality physical education by physical education specialists in Texas. J School Health 2005, 75:313-319.

26. Starc G, Strel J: Tracking excess weight and obesity from childhood to young adulthood: A 12-year prospective cohort study in Slovenia. Public Health Nutr 2011, 14:49-55.

27. Mitsui T, Barajima T, Kanachi M, Shimaoka K: The significant drop in physical activity among children on holidays in a small town in the Tohoku district. J Physiol Anthropol 2010, 29:59-64.

28. Christodoulos AD, Flouris AD, Tokmakidis SP: Obesity and physical fitness of pre-adolescent children during the academic year and the summer period: Effects of organized physical activity. J Child Health Care 2006, 10:199-212.

29. Graf C, Koch B, Dordel S, Schindler-Marlow S, Icks A, Schuller A, BjarnasonWehrens B, Tokarski W, Predel HG: Physical activity, leisure habits and obesity in first-grade children. Eur J Cardiovasc Prev Rehabil 2004, 11:284-290.

30. Harris KC, Kuramoto LK, Schulzer M, Retallack JE: Effect of school-based physical activity interventions on body mass index in children: A metaanalysis. CMAJ 2009, 180:719-726

31. Jurak G, Strel J, Leskošek B, Kovač M: Influence of the Enhanced Physical Education Curriculum on the Physical Fitness of Children. Croat J Edu 2011.

32. Sollerhed AC, Ejlertsson G: Physical benefits of expanded physical education in primary school: Findings from a 3-year intervention study in Sweden. Scand J Med Sci Sports 2008, 18:102-107.

33. Donnelly JE, Greene JL, Gibson CA, Smith BK, Washburn RA, Sullivan DK, DuBose K, Mayo MS, Schmelzle KH, Ryan JJ, et al: Physical Activity Across the Curriculum (PAAC): A randomized controlled trial to promote physical activity and diminish overweight and obesity in elementary school children. Prev Med 2009, 49:336-341.

34. Martinez Vizcaino V, Salcedo Aguilar F, Franquelo Gutierrez R, Solera Martinez M, Sanchez Lopez M, Serrano Martinez S, Lopez Garcia E, Rodriguez Artalejo F: Assessment of an after-school physical activity program to prevent obesity among 9- to 10-year-old children: A cluster randomized trial. Int J Obes (Lond) 2008, 32:12-22.

35. Salcedo Aguilar F, Martinez-Vizcaino V, Sanchez Lopez M, Solera Martinez M Franquelo Gutierrez R, Serrano Martinez S, Lopez-Garcia E, RodriguezArtalejo F: Impact of an after-school physical activity program on obesity in children. J Pediatr 2010, 157:36-42.

36. Kain J, Uauy R, Leyton B, Cerda R, Olivares S, Vio F: Effectiveness of a dietary and physical activity intervention to prevent obesity in school age children. Rev Med Chil 2008, 136:22-30.

37. Connelly JB, Duaso MJ, Butler G: A systematic review of controlled trials of interventions to prevent childhood obesity and overweight: A realistic synthesis of the evidence. Public Health 2007, 121:510-517.

38. Strel J: Sports Educational Chart Ministry of Education and Sport; 1997

39. Kriemler S, Zahner L, Schindler C, Meyer U, Hartmann T, Hebestreit H, Brunner-La Rocca HP, van Mechelen W, Puder JJ: Effect of school based physical activity programme (KISS) on fitness and adiposity in primary schoolchildren: Cluster randomised controlled trial. BMJ 2010, 340:c785.

40. McKenzie TL, Sallis JF, Kolody B, Faucette FN: Long-term effects of a physical education curriculum and staff development program: SPARK. Res Q Exerc Sport 1997, 68:280-291.

41. Kovač M: Učni načrt: program osnovnošolskega izobraževanja Ljubljana: Ministrstvo za šolstvo in šport, Zavod RS za šolstvo; 2001 
42. Kovač M, Sloan S, Starc G: Competencies in physical education teaching: Slovenian teachers' views and future perspectives. Eur Phys Educ Rev 2008, 14:299-323.

43. Vicente-Rodriguez G, Ara I, Perez-Gomez J, Serrano-Sanchez JA, Dorado C, Calbet JAL: High femoral bone mineral density accretion in prepubertal soccer players. Med Sci Sport Exer 2004, 36:1789-1795.

44. Kemper HCG, Twisk JWR, van Mechelen W, Post GB, Roos JC, Lips P: A fifteen-year longitudinal study in young adults on the relation of physical activity and fitness with the development of the bone mass: The Amsterdam Growth and Health Longitudinal Study. Bone 2000, 27:847-853.

45. Foley S, Quinn S, Dwyer T, Venn A, Jones G: Measures of childhood fitness and body mass index are associated with bone mass in adulthood: A 20-year prospective study. J Bone Miner Res 2008, 23:994-1001.

46. Barnekow-Bergkvist M, Hedberg G, Pettersson U, Lorentzon R: Relationships between physical activity and physical capacity in adolescent females and bone mass in adulthood. Scand J Med Sci Sports 2006, 16:447-455.

47. Vicente-Rodriguez G: How does exercise affect bone development during growth? Sports Med 2006, 36:561-569.

48. Ortega FB, Ruiz JR, Castillo MJ, Sjostrom M: Physical fitness in childhood and adolescence: a powerful marker of health. Int J Obesity 2008, 32:1-11.

49. Little NG, Day JAP, Steinke L: Relationship of physical performance to maturation in perimenarchal girls. Am J Hum Biol 1997, 9:163-171.

50. Verstappen FTJ, Twellaar M, Hartgens F, van Mechelen W: Physical fitness and sports skills in relation to sports injuries. A four-year prospective investigation of sports injuries among physical education students. Int J Sports Med 1998, 19:586-591.

51. Sothern MS, Loftin M, Suskind RM, Udall JN, Blecker U: The health benefits of physical activity in children and adolescents: Implications for chronic disease prevention. Eur J Pediatr 1999, 158:271-274.

52. Bevans KB, Fitzpatrick LA, Sanchez BM, Riley AW, Forrest C: Physical education resources, class management, and student physical activity levels: A structure-process-outcome approach to evaluating physical education effectiveness. J Sch Health 2010, 80:573-580.

53. Singerland M, Oomen J, Borghouts L: Physical activity levels during Dutch primary and secondary school physical education. European Journal of Sport Science 2011, 11:249-257.

54. Simons-Morton BG, Taylor WC, Snider SA, Huang IW, Fulton JE: Observed levels of elementary and middle school children's physical activity during physical education classes. Prev Med 1994, 23:437-441.

\section{Pre-publication history}

The pre-publication history for this paper can be accessed here: http://www.biomedcentral.com/1471-2458/12/61/prepub

doi:10.1186/1471-2458-12-61

Cite this article as: Starc and Strel: Influence of the quality implementation of a physical education curriculum on the physical development and physical fitness of children. BMC Public Health 2012 12:61.

\section{Submit your next manuscript to BioMed Central and take full advantage of:}

- Convenient online submission

- Thorough peer review

- No space constraints or color figure charges

- Immediate publication on acceptance

- Inclusion in PubMed, CAS, Scopus and Google Scholar

- Research which is freely available for redistribution 